\title{
Synthesis and Antileishmanial Activity of 1,2,4,5-Tetraoxanes against Leishmania donovani
}

\author{
Lília I. L. Cabral ${ }^{1,2}$, Sébastien Pomel ${ }^{3}$ (i) , Sandrine Cojean ${ }^{3}$, Patrícia S. M. Amado ${ }^{1,2} \mathbb{1}$, \\ Philippe M. Loiseau ${ }^{3, *}$ and Maria L. S. Cristiano ${ }^{1,2, *(D)}$ \\ 1 Center of Marine Sciences, CCMAR, Gambelas Campus, University of Algarve, UAlg, \\ 8005-139 Faro, Portugal; liliacabral80@gmail.com (L.I.L.C.); patricia.s.amado@gmail.com (P.S.M.A.) \\ 2 Department of Chemistry and Pharmacy, Faculty of Sciences and Technology, FCT, Gambelas Campus, \\ University of Algarve, UAlg, 8005-139 Faro, Portugal \\ 3 Chimiothérapie Antiparasitaire, Université Paris-Saclay, CNRS, BioCIS, 92290 Châtenay-Malabry, France; \\ sebastien.pomel@u-psud.fr (S.P.); sandrine.cojean@u-psud.fr (S.C.) \\ * Correspondence: philippe.loiseau@u-psud.fr (P.M.L.); mcristi@ualg.pt (M.L.S.C.); \\ Tel.: +351-912-074-576 (M.L.S.C.)
}

Received: 23 December 2019; Accepted: 20 January 2020; Published: 22 January 2020

\begin{abstract}
A chemically diverse range of novel tetraoxanes was synthesized and evaluated in vitro against intramacrophage amastigote forms of Leishmania donovani. All 15 tested tetraoxanes displayed activity, with $\mathrm{IC}_{50}$ values ranging from 2 to $45 \mu \mathrm{m}$. The most active tetraoxane, compound LC140, exhibited an $\mathrm{IC}_{50}$ value of $2.52 \pm 0.65 \mu \mathrm{m}$ on $L$. donovani intramacrophage amastigotes, with a selectivity index of 13.5. This compound reduced the liver parasite burden of L. donovani-infected mice by 37\% after an intraperitoneal treatment at $10 \mathrm{mg} / \mathrm{kg} / \mathrm{day}$ for five consecutive days, whereas miltefosine, an antileishmanial drug in use, reduced it by $66 \%$. These results provide a relevant basis for the development of further tetraoxanes as effective, safe, and cheap drugs against leishmaniasis.
\end{abstract}

Keywords: Leishmaniasis; antileishmanial chemotherapy; peroxide-derived antimalarials; tetraoxanes; antimalarials re-purposing

\section{Introduction}

Leishmaniases are neglected diseases caused by protozoan parasites of the genus Leishmania and transmitted by the bite of plebotomine sandflies. Visceral leishmaniasis, the most virulent among leishmaniases, affects mostly tropical and subtropical areas of the world. However, it is spreading out of these areas, namely along southern Europe [1,2]. As with other neglected and poverty-related diseases, most patients suffering from leishmaniases do not benefit from a complete treatment, due to the high cost of available drugs, the need for a long treatment period, low accessibility, an inadequate mode of administration, and drug resistance [3]. These drawbacks have triggered a search for new treatment methods, preferably based on recent technologies. The novel drugs for leishmaniasis should be potent and effective, able to clear the parasite burden in a few days, active against resistant strains of Leishmania donovani, orally available, safe, and affordable by the standards of the affected populations [4].

The increasing use of artemisinin and derivatives has clearly evidenced the potential of peroxides in the treatment of vector-borne diseases [5]. Artemisinins were found to be active against all strains of Plasmodium sp. and have been used as antimalarials for around three decades, mostly in Artemisinin Combination Chemotherapy (ACT) protocols [6]. However, the high cost of artemisinin, associated with the low yield of extraction from its natural source (Artemisia annua), together with some toxicity and a short plasma half-life, leading to complex administration regimens or recrudescence, restricts the therapeutic potential of artemisinins. In addition, recent findings of decreased clinical efficacy of 
ACTs in Southeast Asia due to resistance [7] have raised concerns over the lifetime of this class as antimalarials. In order to overcome these limitations while maintaining efficacy, various synthetic analogues, incorporating the key peroxide pharmacophore of artemisinin, were developed [8,9]. Among these, trioxolanes and tetraoxanes have shown activity against different parasites, such as the protozoans Plasmodium spp. [10-19], Perkinsus spp. [20], and the parasitic flatworms Schistosoma spp [21]. A main advantage of trioxolanes and tetraoxanes is their availability, due to straightforward synthesis from inexpensive starting materials, enabling the preparation of chemically diverse libraries of analogues and a better selection of a lead compound [22,23].

The use of artemisinin and its semi-synthetic derivatives for the treatment of leishmaniases has been proposed by several authors [24-33]. Regarding the potential application of synthetic endoperoxides with antimalarial properties, Cortes et al. [34] reported the antiparasitic activity of a small selection of trioxolanes against promastigote and intramacrophage amastigote forms of Leishmania infantum, at micromolar concentrations, introducing the relevance of synthetic endoperoxides for antileishmanial chemotherapy. Given this observation of the antileishmanial activity of ozonide-type antimalarials, it seemed logical to explore 1,2,4,5-tetraoxanes, which also incorporate the endoperoxide core, although these compounds exhibit an enhanced thermodynamic stability compared with their 1,2,4-trioxolane [35,36] or 1,2,4-trioxane [37] counterparts. This singular thermodynamic stability observed in 1,2,4,5-tetraoxanes was clarified by Gomes et al. [38] through theoretical calculations based on stereoelectronic analysis, where the enhanced stability was attributed to a stereoelectronic 'double anomeric effect' that stabilizes the six-membered ring system.

Therefore, our aim was to synthesize 1,2,4,5-tetraoxanes, analogues of the ozonides already reported to have antileishmanial activity [31]. For comparison, we have also prepared novel unsymmetrical 1,2,4,5-tetraoxanes and 1,2,4-trioxolanes with polar water-solubilizing groups (Table 1), known to reduce neurotoxicity and increase the activity profiles, as reported in previous works based on artemisinin derivatives [39]. In the present contribution, we disclose the low micromolar activity of a range of peroxides comprising 15 tetraoxanes and two trioxolanes against intramacrophage amastigote forms of L. donovani. The results are compared with those of dihydroartemisinin (DHA), artesunate (ATS), and the antileishmanial drug miltefosine. From the tested tetraoxanes, compound LC140 displayed a slight in vivo activity against $L$. donovani. It is worth noting that 1,2,4,5-tetraoxanes are easily prepared, offering the possibility of new candidates with improved pharmacologic profiles.

Table 1. Inhibitory concentrations $\left(\mathrm{IC}_{50}\right)$ of artemisinin derivatives, synthetic 1,2,4-trioxolanes, 1,2,4,5-tetraoxanes, and miltefosine (control) against intramacrophage amastigote forms of Leishmania donovani LV9, evaluation of cytotoxicity $\left(\mathrm{CC}_{50}\right)$ against the macrophage cell line RAW 264.7, selectivity index (SI), and estimated $\mathrm{Clog} P$ values.

\begin{tabular}{|c|c|c|c|c|c|c|}
\hline Entry & Compounds & Structures & $\begin{array}{c}\text { Activity } \\
\mathrm{IC}_{50} \pm \mathrm{SD} \\
(\mu \mathrm{m})\end{array}$ & $\begin{array}{c}\text { Toxicity } \\
\mathrm{CC}_{50} \pm \mathrm{SD} \\
(\mu \mathrm{m})\end{array}$ & SI & ClogP value ${ }^{a}$ \\
\hline (A) & DHA & & $3.07 \pm 0.45$ & $>75.00$ & $>24.00$ & 2.59 \\
\hline (B) & ATS & & $15.00 \pm 0.63$ & $>75.00$ & 5.00 & 2.68 \\
\hline (C) & LC129 & & $16.30 \pm 2.41$ & $>75.00$ & $>4.00$ & 4.66 \\
\hline
\end{tabular}


Table 1. Cont.

\begin{tabular}{|c|c|c|c|c|c|c|}
\hline Entry & Compounds & Structures & $\begin{array}{l}\text { Activity } \\
\mathrm{IC}_{50} \pm \mathrm{SD} \\
(\mu \mathrm{m})\end{array}$ & $\begin{array}{c}\text { Toxicity } \\
\mathrm{CC}_{50} \pm \mathrm{SD} \\
(\mu \mathrm{m})\end{array}$ & SI & ClogP value ${ }^{a}$ \\
\hline (D) & LC136 & & $18.36 \pm 4.97$ & $55.20 \pm 6.30$ & 3.00 & 3.14 \\
\hline (E) & LC137 & & $7.75 \pm 1.12$ & $43.15 \pm 3.25$ & 5.50 & 4.52 \\
\hline (F) & LC139 & & $13.17 \pm 0.03$ & $>50.00$ & $>3.80$ & 2.91 \\
\hline (G) & LC140 & & $2.52 \pm 0.65$ & $34.12 \pm 5.38$ & 13.50 & 3.19 \\
\hline (H) & LC141 & & $18.36 \pm 3.19$ & $>100.00$ & 5.40 & 5.24 \\
\hline (I) & LC146 & & $16.00 \pm 1.05$ & $>100.00$ & $>6.20$ & 3.59 \\
\hline (J) & LC153 & & $17.33 \pm 2.02$ & $>50.00$ & $>2.80$ & 3.64 \\
\hline (K) & LC159 & & $44.49 \pm 1.13$ & ND & ND & 4.39 \\
\hline (L) & LC163 & & $12.16 \pm 3.96$ & $>50.00$ & $>4.10$ & 3.41 \\
\hline (M) & LC165 & & $8.79 \pm 1.79$ & $>75.00$ & $>8.00$ & 3.35 \\
\hline$(\mathrm{N})$ & LC167 & & $14.97 \pm 0.07$ & $>50.00$ & $>3.30$ & 4.67 \\
\hline (O) & LC177 & & $17.57 \pm 0.85$ & $>50.00$ & $>2.80$ & 4.89 \\
\hline (P) & LC179 & & $29.05 \pm 0.26$ & ND & ND & 4.16 \\
\hline (Q) & LC180 & & $28.97 \pm 1.95$ & ND & ND & 3.76 \\
\hline (R) & PA5 & & $19.22 \pm 0.11$ & $>50.00$ & $>2.60$ & 4.83 \\
\hline (S) & PA6 & & $17.74 \pm 2.78$ & $>50.00$ & $>2.80$ & 4.53 \\
\hline (T) & $\begin{array}{c}\text { HePC } \\
\text { (Miltefosine) }\end{array}$ & & $0.71 \pm 0.20$ & $54.30 \pm 2.14$ & 76.40 & 4.22 \\
\hline
\end{tabular}

ND—not determined. ${ }^{a}$ Calculated using ALOGPS software (http://www.vcclab.org/lab/alogps/).

\section{Results and Discussion}

All tested peroxides showed antiproliferative activity against intramacrophage amastigote forms of $L$. donovani, exhibiting $\mathrm{IC}_{50}$ values in a range from 2 to $45 \mu \mathrm{m}$ and clearly demonstrating the susceptibility of L. donovani parasites to the peroxide chemotype (Table 1, entries A-T). Overall, the values are higher than those obtained for miltefosine $(0.71 \pm 0.20 \mu \mathrm{m}$, Table 1 , entry $\mathrm{T})$, using the same parasite strain and similar experimental conditions, but the tetraoxanes appeared generally to be less toxic. Among the tested tetraoxanes, three compounds exhibited an $\mathrm{IC}_{50}$ value lower than $10 \mu \mathrm{m}$ (compounds LC140, LC137, and LC165; $2.52 \pm 0.65,7.75 \pm 1.12$, and $8.79 \pm 1.79 \mu \mathrm{m}$, respectively; Table 1, entries G, E, and M), LC165 being significantly less toxic than miltefosine. Interestingly, 
compounds LC137 and LC140 may be obtained from commercially available materials with only two synthetic steps.

Our results indicate that the activities shown by tetraoxanes and trioxolanes with a close chemical structure are similar. For the two tested trioxolanes, $\mathrm{LC} 129$ and LC136, the $\mathrm{IC}_{50}$ values ranged between $16.30 \pm 2.41$ and $18.36 \pm 4.97 \mu \mathrm{m}$ (Table 1 ; entries $C, D$ ). These values are similar to those obtained for tetraoxanes LC163, LC177, and PA5 (Table 1; entries L, O, and R). The $\mathrm{IC}_{50}$ value obtained for tetraoxane LC165 is also very close to that previously reported for the corresponding trioxolane [34].

From our results, it is possible to conclude that the chemical nature of the cyclohexyl substituent has an impact on activity, for both tetraoxanes and trioxolanes. However, due to the relatively narrow range of values, differences are possibly related to variations in $\mathrm{Clog}$, with different drug uptakes and pharmacokinetics. Quite interestingly, the activities of all of the artemisinin-derived compounds assayed also lie in the low micromolar range. DHA and tetraoxane LC140 exhibited similar IC 50 values $(3.07 \pm 0.45 \mu \mathrm{m}$ and $2.52 \pm 0.65 \mu \mathrm{m})$, respectively (Table 1; entry A and Table 1; entry G), while the more polar ATS was shown to be slightly less active $(15.00 \pm 0.63 \mu \mathrm{m}$ (Table 1 ; entry B)).

Our results showed that the activities exhibited by the synthetic tetraoxanes LC137, LC140, and LC165 are similar to those of the semisynthetic artemisinin derivatives (DHA and ATS), disclosing the potential of tetraoxanes to be anti-proliferative agents against intramacrophage amastigote forms of L. donovani. The peroxide bridge in the synthetic compounds should play a role in the mechanism of action, as seen for artemisinin and its semisynthetic derivatives. It has been observed that artemisinin mediates its toxicity against Leishmania promastigotes by inducing a redox imbalance following the generation of reactive oxygen species (ROS) secondary to cleavage of its endoperoxide bridge, the process terminating in a caspase-independent, apoptotic mode of cell death $[25,28,29,33]$. It is important to highlight that 1,2,4,5-tetraoxanes have been reported to possess a higher stability and better antimalarial activity compared to their ozonide counterparts [37]. In this work, we can observe that both classes of endoperoxides exhibit similar anti-leishmanial activities, though better $\mathrm{IC}_{50}$ values in tetraoxanes LC137, LC140, and LC165 were observed. Future studies for comparison of metabolic properties should be considered.

Concerning the in vivo antileishmanial evaluation, the treatment regimen at a dose of $10 \mathrm{mg} / \mathrm{kg} / \mathrm{day}$, for five consecutive days, corresponds to the classical flowchart used by Drugs for Neglected Diseases Initiative (DNDi), the non-governmental organization (NGO) in charge of drug development against Neglected Diseases. DNDi considers further development for a compound only if a significant activity can be demonstrated under these stringent conditions.

In vivo, we observed that one mouse among eight mice died in each treated batch (LC137 and LC140) one day after the last treatment. This datum is in relation to a toxicity, whereas no other apparent signs of toxicity were observed (Figure 1). At this early stage, no deeper investigation was performed at the toxicological level. Under these conditions, only the in vivo activity of miltefosine was statistically significant, with a reduction of $66 \%$ of the parasite burden in the liver, whereas compound LC140 reduced the liver parasite burden by $37 \%$ (Table 2). These results justify further pharmacomodulations in order to optimize this series and to obtain a better in vivo effect at $10 \mathrm{mg} / \mathrm{kg} /$ day for five consecutive days, these regimen conditions being sine qua non to go further.

Table 2. In vivo activity of tetraoxanes LC137 and LC140, and miltefosine, a reference antileishmanial drug, on L. donovani/Balb/C mice. Compounds were administered intraperitonially, at a dose of 10 $\mathrm{mg} / \mathrm{kg} /$ day, for five consecutive days.

\begin{tabular}{cccccc}
\hline Batch & $\begin{array}{c}\text { Number of } \\
\text { Mice }\end{array}$ & $\begin{array}{c}\text { Number of } \\
\text { Dead Mice }\end{array}$ & Treatment Regimen & $\begin{array}{c}\text { LDU (10 })^{\mathbf{8}} \pm \\
\text { SD }\end{array}$ & $\begin{array}{c}\text { \% reduction of } \\
\text { Parasite Burden in } \\
\text { the Liver }\end{array}$ \\
\hline LC137 $10 \mathrm{mg} / \mathrm{kg}$ & 8 & 1 & $10 \mathrm{mg} / \mathrm{kg} / \mathrm{d} \times 5(\mathrm{IP})$ & $3.92 \pm 1.03$ & 16.40 \\
$\mathrm{LC} 14010 \mathrm{mg} / \mathrm{kg}$ & 8 & 1 & $10 \mathrm{mg} / \mathrm{kg} / \mathrm{d} \times 5$ (IP) & $2.95 \pm 0.69$ & 37.29 \\
Miltefosine & 8 & 0 & $10 \mathrm{mg} / \mathrm{kg} / \mathrm{d} \times 5$ (IV) & $1.60 \pm 0.45$ & 65.9 \\
Control & 10 & 0 & Treated with the excipient & $4.70 \pm 0.71$ & - \\
\hline
\end{tabular}




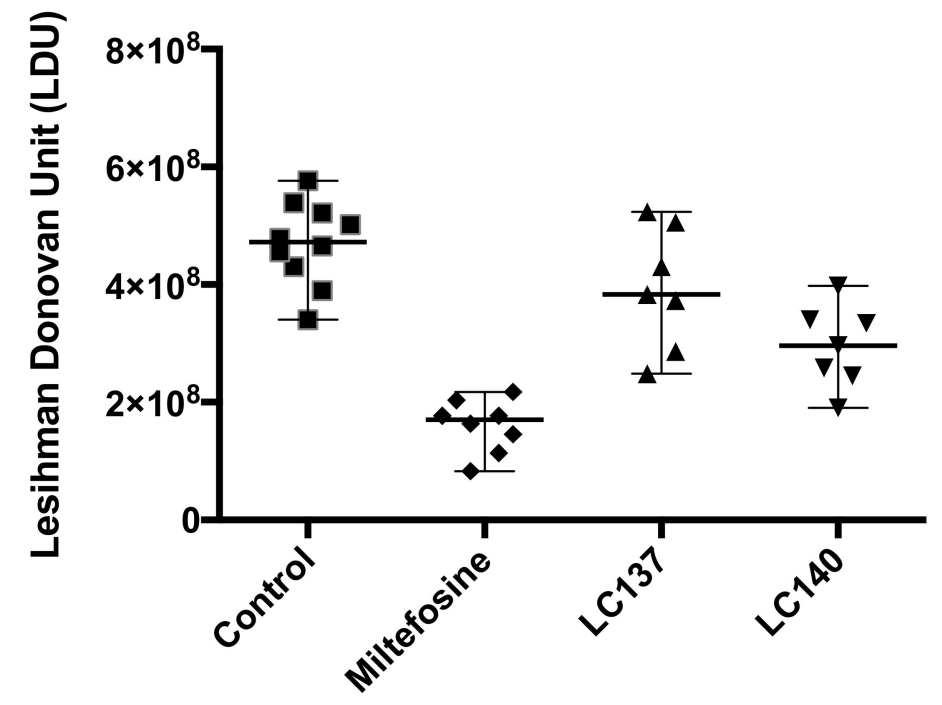

Figure 1. In vivo activity of tetraoxanes LC137 and LC140, and miltefosine, a reference antileishmanial drug.

\section{Materials and Methods}

The structures of the 15 tetraoxanes assayed against intramacrophage amastigote forms of L. donovani differ only in the chemical nature of the cyclohexyl substituent (Table 1). From this library, only compounds L137 [40], LC140 [14], L153 [41], and LC163 [19] were previously reported in the context of antiparasitic chemotherapy (compound LC163 was disclosed by our group). For comparative purposes, we have also evaluated the activity of a small library of 1,2,4-trioxolanes and that of the known peroxide-based antiplasmodial drugs dihydroartemisinin (DHA) and artesunate (ATS) (Table 1). The 1,2,4,5-tetraoxanes and 1,2,4-trioxolanes were synthesized by adapting procedures described in the literature. The synthetic procedures and experimental details for the preparation and chemical characterization of compounds are included in the Supplementary Materials. The inhibitory effect of each compound tested against $L$. donovani is expressed as $\mathrm{IC}_{50}$ (concentration of drug inhibiting parasite growth by 50\%), according to a protocol previously described [42]. The cytotoxicity was evaluated on the mouse monocyte/macrophage cell line RAW 264.7, as the parasite host cells, and is expressed as $\mathrm{CC}_{50}$ (cytotoxic concentration inhibiting the cell growth by $50 \%$ ) following a previously described protocol [42]. The selectivity index (SI) is defined as the ratio $\mathrm{CC}_{50} / \mathrm{IC}_{50}$. Miltefosine was used as reference drug. Results are compiled in Table 1.

For in vivo evaluation, all procedures involving animals were conducted in compliance with the standards for animal experiments and were approved by the local committee for animal care (0858.01/2014, Versailles, France). The protocol of evaluation on the L. donovani/Balb/C mice model is presented by Morais et al. [43] Two 1,2,4,5-tetraoxane derivatives were evaluated by an intraperitoneal route at $10 \mathrm{mg} / \mathrm{kg} /$ day on five consecutive days. Miltefosine, as the control, was evaluated at the same dose by an intravenous route. Animals were sacrificed three days after the end of treatment. Livers and spleens were weighed and drug activity was estimated microscopically by counting the number of amastigotes/500 liver cells in Giemsa-stained impression smears to calculate the Leishmania donovani units (LDUs) for liver parasite burdens, using Stauber's formula. The mean number of parasites per gram of liver among treatment groups and controls was compared. Three independent counts were performed and the results are expressed as the mean values \pm SD. The parasite burden of treatment groups and controls were compared using the Kruskal-Wallis nonparametric analysis of variance test for comparing two groups. Significance was established for a $p$ value $<0.05$. 


\section{Conclusions}

The results presented herein unveil the potential of tetraoxanes as anti-proliferative agents against intramacrophage amastigote forms of L. donovani. Compounds LC137, LC140, and LC165 (Table 1) appear to be the most promising, combining a comparatively high activity and low toxicity. In vivo, LC140 appears to be a lead to investigate further through new pharmacomodulations (see Table 2).

Our data indicate that tetraoxanes and trioxolanes with a close chemical structure exhibit similar activity. Also, the nature of the substituents attached to the endoperoxide core (tetraoxane or trioxolane) appears to have a relatively modest effect on activity. Major aspects (accumulation, bioactivation, targets involved, etc.) underlining the action of the tested compounds (including artemisinin derivatives) require a deep and pluridisciplinary investigation, to unravel the mode of action of these compounds.

Supplementary Materials: The following are available online, S.1: Synthetic procedures and experimental details for the synthesis and chemical characterization of compounds. S.1.1: General methods and analytical techniques. S.1.2: Preparation of intermediate building blocks. S.1.2.1: Preparation of 3-chloro-1,2-benzisothiazole-1,1-dioxide. S.1.2.2: Preparation of 1-phenyl-1H-tetrazol-5(4H)-one, 1-methyl-1H-tetrazole-5-amine and 2-methyl-2H-tetrazole-5-amine. S.1.2.3: Preparation of tert-butyl(4-aminobutyl)carbamate, LC64. S.1.3: Synthetic route to trixolanes. S.1.3.1: Synthesis of 1,2,4-trioxolanes LC129 and LC136. S.1.4: Synthetic route to tetraoxanes. S.1.4.1: Synthesis of 1,2,4,5-tetraoxanes. S.2: Spectra of the compounds. S3. In vitro antileishmanial screening. S3.1: Cell lines and cultures. S3.2: In vitro antileishmanial evaluation on intramacrophage amastigotes. S3.3: In vitro antileishmanial evaluation on Leishmania donovani axenic amastigotes. S3.4: Evaluation of compounds cytotoxicity. S4. In vivo antileishmanial screening. S4.1: Animal and housing. S4.2: Evaluation of in vivo acute toxicity by an intraperitoneal route. S4.3: In vivo antileishmanial evaluation. S.5: References.

Author Contributions: Conceptualization: L.I.L.C., P.S.M.A., S.C., and M.L.S.C.; methodology (synthesis of the compounds): L.I.L.C. and P.S.M.A.; methodology (in vitro tests): S.C.; (in vivo tests): S.P.; validation: M.L.S.C. and P.M.L.; formal analysis: M.L.S.C. and P.M.L.; investigation: L.I.L.C., P.S.M.A., S.C., M.L.S.C., and P.M.L.; resources: M.L.S.C. and P.M.L.; writing-original draft preparation: L.I.L.C., P.S.M.A., S.C., and M.L.S.C.; writing-review and editing: M.L.S.C. and P.M.L.; project administration: M.L.S.C.; funding acquisition: M.L.S.C. and P.M.L. All authors have read and agreed to the published version of the manuscript.

Funding: This research was funded by Fundação para a Ciência e a Tecnologia (FCT), and FEDER/COMPETE 2020-UE, through projects UID/Multi/04326/2019 (Centre of Marine Sciences-CCMAR) and PTDC/MAR-BIO/4132/2014.

Acknowledgments: The authors gratefully acknowledge Fundação para a Ciência e a Tecnologia (FCT), and FEDER/COMPETE 2020-UE, through projects UID/Multi/04326/2019 (Centre of Marine Sciences-CCMAR) and PTDC/MAR-BIO/4132/2014. Lília I. L. Cabral and Patrícia S. M. Amado thank CCMAR and FCT for fellowships (from project PTDC/MAR-BIO/4132/2014 and grant SFRH/BD/130407/2017, respectively).

Conflicts of Interest: The authors declare no conflicts of interest.

\section{References}

1. Davis, A.J.; Murray, H.W.; Handman, E. Drugs against leishmaniasis: A synergy of technology and partnerships. Trends Parasitol. 2004, 20, 73-76. [CrossRef] [PubMed]

2. Rajasekaran, R.; Chen, Y.-P.P. Potential therapeutic targets and the role of technology in developing novel antileishmanial drugs. Drug Discov. Today 2015, 20, 958-968. [CrossRef] [PubMed]

3. Freitas-Junior, L.H.; Chatelain, E.; Kim, H.A.; Siqueira-Neto, J.L. Visceral leishmaniasis treatment: What do we have, what do we need and how to deliver it? Int. J. Parasitol. Drugs Drug Resist. 2012, 2, 11-19. [CrossRef] [PubMed]

4. WHO. Fourth WHO Report on Neglected Tropical Diseases; WHO: Geneva, Switzerland, 2017.

5. Ho, W.E.; Peh, H.Y.; Chan, T.K.; Wong, W.S.F. Artemisinins: Pharmacological actions beyond anti-malarial. Pharmacol. Ther. 2014, 142, 126-139. [CrossRef]

6. World Health Organization. World Malaria Report; World Health Organization: Geneva, Switzerland, 2017.

7. Dondorp, A.M.; Nosten, F.; Yi, P.; Das, D.; Phyo, A.P.; Tarning, J.; Lwin, K.M.; Ariey, F.; Hanpithakpong, W.; Lee, S.J.; et al. Artemisinin Resistance in Plasmodium falciparum Malaria. N. Engl. J. Med. 2009, 361, 455-467. [CrossRef]

8. Tang, Y.; Dong, Y.; Vennerstrom, J.L. Synthetic peroxides as antimalarials. Med. Res. Rev. 2004, 24, 425-448. [CrossRef]

9. Muregi, F.W.; Ishih, A. Next-generation antimalarial drugs: Hybrid molecules as a new strategy in drug design. Drug Dev. Res. 2010, 71, 20-32. [CrossRef] 
10. Vennerstrom, J.L.; Arbe-Barnes, S.; Brun, R.; Charman, S.A.; Chiu, F.C.K.; Chollet, J.; Dong, Y.; Dorn, A.; Hunziker, D.; Matile, H.; et al. Identification of an antimalarial synthetic trioxolane drug development candidate. Nature 2004, 430, 900-904. [CrossRef]

11. Tang, Y.; Wittlin, S.; Charman, S.A.; Chollet, J.; Chiu, F.C.K.; Morizzi, J.; Johnson, L.M.; Tomas, J.S.; Scheurer, C.; Snyder, C.; et al. The comparative antimalarial properties of weak base and neutral synthetic ozonides. Bioorganic Med. Chem. Lett. 2010, 20, 563-566. [CrossRef]

12. Vennerstrom, J.L.; Dong, Y.; Chollet, J.; Matile, H. Spiro and Dispiro 1,2,4-Trioxolane Antimalarials. U.S. Patent 6,486,199B, 2012.

13. Charman, S.A.; Arbe-Barnes, S.; Bathurst, I.C.; Brun, R.; Campbell, M.; Charman, W.N.; Chiu, F.C.K.; Chollet, J.; Craft, J.C.; Creek, D.J.; et al. Synthetic ozonide drug candidate OZ439 offers new hope for a single-dose cure of uncomplicated malaria. Proc. Natl. Acad. Sci. USA 2011, 108, 4400-4405. [CrossRef]

14. Marti, F.; Chadwick, J.; Amewu, R.K.; Burrell-Saward, H.; Srivastava, A.; Ward, S.A.; Sharma, R.; Berry, N.; O'Neil, P.M. Second generation analogues of RKA182: Synthetic tetraoxanes with outstanding in vitro and in vivo antimalarial activities. Med. Chem. Comm. 2011, 2, 661-665. [CrossRef]

15. O'Neill, P.M.; Sabbani, S.; Nixon, G.L.; Schnaderbeck, M.; Roberts, N.L.; Shore, E.R.; Riley, C.; Murphy, B.; McGillan, P.; Ward, S.A.; et al. Optimisation of the synthesis of second generation 1,2,4,5 tetraoxane antimalarials. Tetrahedron 2016, 72, 6118-6126. [CrossRef]

16. Kumar, N.; Singh, R.; Rawat, D.S. Tetraoxanes: Synthetic and Medicinal Chemistry Perspective. Med. Res. Rev. 2010, 32, 581-610. [CrossRef] [PubMed]

17. Kumar, N.; Sharma, M.; Rawat, D.S. Medicinal Chemistry Perspectives of Trioxanes and Tetraoxanes. Curr. Med. Chem. 2011, 18, 3889-3928. [CrossRef] [PubMed]

18. Kumar, N.; Khan, S.I.; Atheaya, H.; Mamgain, R.; Rawat, D.S. Synthesis and in vitro antimalarial activity of tetraoxane-amine/amide conjugates. Eur. J. Med. Chem. 2011, 46, 2816-2827. [CrossRef] [PubMed]

19. Lobo, L.; Cabral, L.I.L.; Sena, M.I.; Guerreiro, B.; Rodrigues, A.S.; Andrade-Neto, V.F.; Cristiano, M.L.S.; Nogueira, F. New endoperoxides highly active in vivo and in vitro against artemisinin-resistant Plasmodium falciparum. Malar. J. 2018, 17, 1-11. [CrossRef] [PubMed]

20. Araujo, N.C.P.; Afonso, R.; Bringela, A.; Cancela, M.L.; Cristiano, M.L.S.; Leite, R.B. Peroxides with antiplasmodial activity inhibit proliferation of Perkinsus olseni, the causative agent of Perkinsosis in bivalves. Parasitol Int. 2013, 62, 575-582. [CrossRef]

21. Cowan, N.; Yaremenko, I.A.; Krylov, I.B.; Terent'ev, A.O. Keiser, Elucidation of the in vitro and in vivo activities of bridged 1,2,4-trioxolanes, bridged 1,2,4,5-tetraoxanes, tricyclic monoperoxides, silyl peroxides, and hydroxylamine derivatives against Schistosoma mansoni. J. Bioorg. Med. Chem. 2015, 23, 5175-5181. [CrossRef]

22. Opsenica, D.M.; Šolaja, B.A. Antimalarial peroxides. J. Serb. Chem. Soc. 2009, 74, 1155-1193. [CrossRef]

23. Amewu, R.K.; Chadwick, J.; Hussain, A.; Panda, S.; Rinki, R.; Janneh, O.; Ward, S.A.; Miguel, C.; Burrell-Saward, H.; Vivas, L.; et al. Synthesis and evaluation of the antimalarial, anticancer, and caspase 3 activities of tetraoxane dimers. Bioorg. Med. Chem. 2013, 21, 7392-7397. [CrossRef]

24. Yang, D.M.; Liew, F.Y. Effects of qinghaosu (artemisinin) and its derivatives on experimental cutaneous leishmaniasis. Parasitology 1993, 106, 7-11. [CrossRef]

25. Sen, R.; Bandyopadhyay, S.; Dutta, A.; Mandal, G.; Ganguly, S.; Saha, P.; Chatterjee, M. Artemisinin triggers induction of cell-cycle arrest and apoptosis in Leishmania donovani promastigotes. J. Med. Microbiol. 2007, 56, 1213-1218. [CrossRef]

26. Lezama-Dávila, C.M.; Satoskar, A.R.; Úc-Encalada, M.; Isaac-Márquez, R.; Isaac-Márquez, A.P. Leishmanicidal Activity of Artemisinin, Deoxoartemisinin, Artemether and Arteether. Nat. Prod. Commun. 2007, 2, 1-4. [CrossRef]

27. Chollet, C.; Crousse, B.; Bories, C.; Bonnet-Delpon, D.; Loiseau, P.M. In vitro antileishmanial activity of fluoro-artemisinin derivatives against Leishmania donovani. Biomed. Pharm. 2008, 62, 462-465. [CrossRef]

28. Sen, R.; Ganguly, S.; Saha, P.; Chatterjee, M. Efficacy of artemisinin in experimental visceral leishmaniasis. Int. J. Antimicrob. Agents. 2010, 36, 43-49. [CrossRef]

29. Sen, R.; Saha, P.; Sarkar, A.; Ganguly, S.; Chatterjee, M. Iron enhances generation of free radicals by artemisinin causing a caspase-independent, apoptotic death in Leishmania donovani promastigotes. Free Radic. Res. 2010, 44, 1289-1295. [CrossRef]

30. Dehkordi, N.M.; Ghaffarifar, F.; Hassan, Z.M.; Heydari, F.E. In Vitro and In Vivo Studies of Anti leishmanial Effect of Artemether on Leishmania infantum. Jundishapur J. Microbiol. 2013, 6, e6379. [CrossRef] 
31. Want, M.Y.; Islamuddin, M.; Chouhan, G.; Ozbak, H.A.; Hemeg, H.A.; Dasgupta, A.K.; Chattopadhyay, A.P.; Afrin, F. Therapeutic efficacy of artemisinin-loaded nanoparticles in experimental visceral leishmaniasis. Colloids Surf. B Biointerfaces 2015, 130, 215-221. [CrossRef] [PubMed]

32. Want, M.Y.; Islammudin, M.; Chouhan, G.; Ozbak, H.A.; Hemeg, H.A.; Chattopadhyay, A.P.; Afrin, F. Nanoliposomal artemisinin for the treatment of murine visceral Leishmaniasis. Int. J. Nanomed. 2017, 12, 2189-2204. [CrossRef]

33. Sarkar, S.D.; Sarkar, D.; Sarkar, A.; Dighal, A.; Chakrabarti, S.; Staniek, K.; Gille, L.; Chatterjee, M. The leishmanicidal activity of artemisinin is mediated by cleavage of the endoperoxide bridge and mitochondrial dysfunction. Parasitology 2019, 146, 511-520. [CrossRef]

34. Cortes, S.; Albuquerque, A.; Cabral, L.I.L.; Lopes, L.; Campino, L.; Cristiano, M.L.S. In Vitro Susceptibility of Leishmania infantum to Artemisinin Derivatives and Selected Trioxolanes. Antimicrob. Agents Chemother. 2015, 59, 5032-5035. [CrossRef]

35. Amewu, R.K.; Stachulski, A.V.; Ward, S.A.; Berry, N.G.; Bray, P.G.; Davies, J.; Labat, G.; Vivas, L.; O’Neill, P.M. Design and synthesis of orally active dispiro 1,2,4,5-tetraoxanes; synthetic antimalarials with superior activity to artemisinin. Org. Biomol. Chem. 2006, 4, 4431-4436. [CrossRef]

36. O'Neill, P.M.; Amewu, R.K.; Nixon, G.L.; ElGarah, F.B.; Mathirut, M.; Chadwick, J.; Shone, A.E.; Vivas, L.; Lander, H.; Barton, V.; et al. Identification of a 1,2,4,5-Tetraoxane Antimalarial Drug-Development Candidate (RKA 182) with Superior Properties to the Semisynthetic Artemisinins. Angew. Chem. Int. Ed. 2010, 49, 5693-5697. [CrossRef]

37. Ellis, G.L.; Amewu, R.K.; Sabbani, S.; Stocks, P.A.; Shone, A.; Stanford, D.; Gibbons, P.; Davies, J.; Vivas, L.; Charnaud, S.; et al. Two-Step Synthesis of Achiral Dispiro-1,2,4,5-tetraoxanes with Outstanding Antimalarial Activity, Low Toxicity, and High-Stability Profiles. J. Med. Chem. 2008, 51, 2170-2177. [CrossRef] [PubMed]

38. Gomes, G.P.; Vil', V.; Terent'ev, A.; Alabugin, I.V. Stereoelectronic source of the anomalous stability of bis-peroxides. Chem. Sci. 2015, 6, 6783-6791. [CrossRef] [PubMed]

39. Haynes, R.K. From Artemisinin to New Artemisinin Antimalarials: Biosynthesis, Extraction, Old and New Derivatives, Stereochemistry and Medicinal Chemistry Requirements. Curr. Top. Med. Chem. 2006, 6, 509-537. [CrossRef] [PubMed]

40. Terent'ev, A.O.; Kutkin, A.V.; Starikova, Z.A.; Antipin, M.Y.; Ogibin, Y.N.; Nikishin, G.I. New preparation of 1,2,4,5-tetraoxanes. Synthesis 2004, 14, 2356-2366. [CrossRef]

41. Wang, X.; Zhao, Q.; Vargas, M.; Dong, Y.; Sriraghavan, K.; Keiser, J.; Vennerstrom, J.L. The activity of dispiro peroxides against Fasciola hepatica. Bioorg. Med. Chem. Lett. 2011, 21, 5320-5323. [CrossRef]

42. Balaraman, K.; Vieira, N.C.; Moussa, F.; Vacus, J.; Cojean, S.; Pomel, S.; Bories, C.; Figadère, B.; Kesavan, V.; Loiseau, P.M. In vitro and in vivo antileishmanial properties of a 2- $n$-propylquinoline hydroxypropyl $\beta$-cyclodextrin formulation and pharmacokinetics via intravenous route. Biomed. Pharmacother. 2015, 76, 127-133. [CrossRef]

43. Morais, A.R.V.; Silva, A.L.; Cojean, S.; Balaraman, K.; Bories, C.; Pomel, S.; Barratt, G.; Egito, E.S.T.; Loiseau, P.M. In-vitro and in-vivo antileishmanial activity of inexpensive Amphotericin B formulations: Heated Amphotericin B and Amphotericin B-loaded microemulsion. Exp. Parasitol. 2018, 192, 85-92. [CrossRef]

(C) 2020 by the authors. Licensee MDPI, Basel, Switzerland. This article is an open access article distributed under the terms and conditions of the Creative Commons Attribution (CC BY) license (http://creativecommons.org/licenses/by/4.0/). 